\title{
PREMEDICATION WITH DROPERIDOL: A DOUBLE-BLIND STUDY
}

\author{
C. R. Stephen, M.D. ${ }^{*}$
}

Tradirion has DiCtated that premedication prior to induction of anaesthesia shall include a narcotic drug and an anticholinergic compound. Like many other traditions in modern society, this concept has been questioned in recent years, and new ideas are being proposed. The purpose of premedication primarily is to allay fear and apprehension, and hopefully to do so without depressing the vital functions of respiration and circulation. These aims can be approached in one of two ways, or in both. The first can be called psychological, and implies an understanding and time-consuming preoperative visit with the patient, answering questions and explaining procedures, thereby nullifying the often all-consuming fear of the unknown. Unfortunately, the anaesthesiologist of today frequently does not have the time to spend in this exercise. Therefore, he relies more heavily on the second approach, pharmacological premedication, which may or may not have its predicted action. Often the action of the drug or drugs prescribed may prove of little benefit to the patient, or sometimes the effect may be more depressing to the vital functions than desired. The problem of premedication is still present, and the solution may await the advent of new sedative drugs.

The purpose of this study was to evaluate the effectiveness and safety of one such new compound, droperidol, for premedication prior to anaesthesia and surgery. This drug is one of the components of Innovar (a 50:1 mixture of droperidol and fentanyl) and represents a relatively new chemical configuration, a butyrophenone, in medical pharmacology (Fig. 1). It is described as being a tranquillizer and a sedative.

Droperidol was synthesized by Paul Janssen in Belgium. ${ }^{1}$ In dogs, utilizing intravenous doses comparable to those recommended in humans ( 5 to $10 \mathrm{mg} / 70$ $\mathrm{kg}$ ), a significant reduction in spontaneous motor activity was induced, along with a loss of responsiveness to normal environmental sounds and a tendency to sleep. ${ }^{2}$ However, the animals could be aroused by loud sounds or by handling. In this dosage range, the rate of respiration was slowed, but there was a compensatory increase in tidal volume, so that the minute volume was either unchanged or increased.

The effects on the cardiovascular system in dogs were consistent. In the abovementioned dose range, intravenous administration caused a transient 5 to 10 per cent decrease in systolic blood pressure, which was followed by some slowing of the heart rate. The effect on ventricular contractile force, as measured from a strain gauge placed on the right ventricle, was equivocal. Likewise, there was little or no effect on cardiac output. However, total peripheral resistance was

Department of Anesthesiology, University of Texas (Southwestern) Medical School, and Parkland Memorial Hospital, Dallas, Texas. 


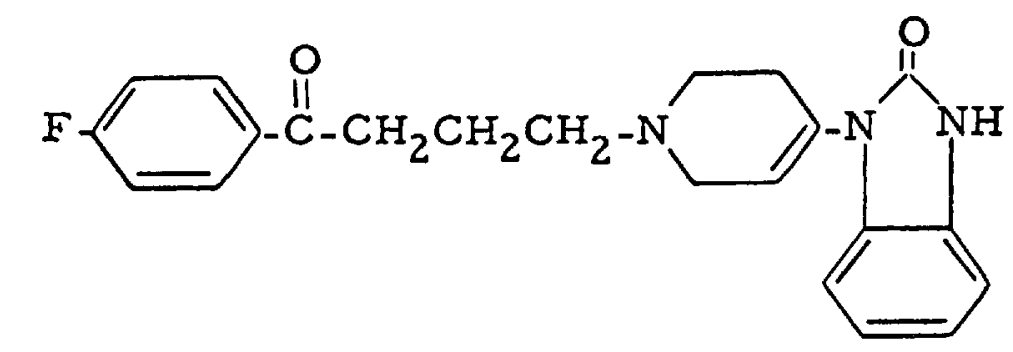

\section{$1-(1-[4-(p-$ fluorophenyl) -4-oxobutyl] $-1,2$, 3, 6-tetrahydro-4-pyridyl)-2-benzimidazolinone}

Figure 1. Structure of droperidol.

reduced by droperidol, and this action was shown to be due to a specific adrenergic blocking effect, similar in nature to that noted with chlorpromazine. This effect could explain the transient reduction in blood pressure.

It was also found that in dogs droperidol exerted an antiarrhythmic effect, in that it prevented epinephrine and chloroform-epinephrine induced arrhythmias. In an additional study in dogs, droperidol was shown to have a marked antiemetic action.

The actions of droperidol in humans have been studied by several groups of investigators. De Castro and Mundeleer ${ }^{3}$ observed a depression of psychic and motor tone in doses up to $50 \mathrm{mg}$ slowly administered intravenously. The movements of patients became slow and uncertain, speech was slurred and replies to questions delayed, and an indifference to or disconnection from the environment developed. If left alone, the patients would lie quietly with their eyes closed; however, normal orientation to place and person was preserved. The onset of action of the drug was rapid (five to ten minutes), and its peak effect lasted for two to four hours.

Ferrari and his group 4 confirmed these findings and in a series of 25 patients who were given droperidol $5 \mathrm{mg}$ intravenously showed that no significant changes occurred in arterial $\mathrm{pH}$ and blood gas values and that blood pressure remained stable. ${ }^{5}$ A lack of respiratory depression, stability of the cardiovascular system, and antiemetic properties, in the presence of significant tranquillization, were demonstrated by both study groups.

\section{METHOD OF STUDY}

Identical $2 \mathrm{ml}$ ampules were supplied which were labelled only by individual number. One group contained droperidol $5 \mathrm{mg}$, one group secobarbital $100 \mathrm{mg}$, and the third group saline. The code was not broken until the study was completed. Only one technician was involved in interviewing patients to determine their subjective reactions, and an anaesthesiologist assessed the patient objectively along with the technician just prior to induction of anaesthesia.

The study was carried out over a period of six months. Five to eight patients 
were selected at random from the operating schedule the day before surgery. The technician then reviewed the records of these patients, interviewed them, and made appropriate notations on a special study form which had been prepared. An ampule of solution was left for the ward nurse to administer intramuscularly one to two hours before surgery the next day. The only other premedicant drug received by some patients was atropine.

On arrival in the induction room the next day, the patient was again interviewed by the technician, and an objective assessment was made by the anaesthesiologist who was to administer the anaesthetic. The patients were again interviewed in the recovery room following completion of surgery and anaesthesia.

\section{Results}

A total of 514 adult patients were included in the study, of whom 62 per cent were women (Table I). The age, weight, and physical status distributions are shown in Tables II, III, and IV. Taking into consideration these several characteristics, the three drug groups had a homogeneous distribution as determined by the chisquare statistic and the analysis of variance test.

TABLE I

Patient Characteristics

\begin{tabular}{lcccc}
\hline \hline Patients & Droperidol & Secobarbital & Placebo & Total \\
\hline Male & 64 & 62 & 69 & 195 \\
Female & 103 & 117 & 99 & 319 \\
Total & 167 & 179 & 168 & 514 \\
\hline
\end{tabular}

TABLE II

\begin{tabular}{lcccr}
\hline \hline Age & Droperidol & Secobarbital & Placebo & Total \\
\hline $10-19$ & 17 & 18 & 8 & 43 \\
$20-29$ & 41 & 27 & 44 & 112 \\
$30-39$ & 34 & 55 & 35 & 124 \\
$40-49$ & 21 & 26 & 29 & 76 \\
$50-59$ & 26 & 22 & 23 & 71 \\
$60-69$ & 23 & 25 & 20 & 68 \\
$70-79$ & 3 & 5 & 8 & 16 \\
$80-89$ & 2 & 1 & 1 & 4 \\
Total & 167 & 179 & 168 & 514 \\
Mean & 39.0 & 41.0 & 41.4 & 40.5 \\
\hline
\end{tabular}

Table $\mathrm{V}$ lists the incidence of a history of disease as elicited from the interviews and the patients' records. The similarity of these distributions again indicates the homogeneity of the study groups. The type of surgery performed on these patients included all surgical specialties except neurosurgery.

During the interview the afternoon before surgery, the emotional status of each patient was assessed (Table VI). Most of the patients were considered to be alert. About 15 per cent in each group were judged to be nervous or restless. In the interval between this interview and the administration of the study drug, about 
TABLE III

\begin{tabular}{lcccc}
\hline \hline Weight (lbs) & Droperidol & Secobarbital & Placebo & Total \\
\hline $70-99$ & 9 & 4 & 4 & 17 \\
$100-129$ & 37 & 43 & 35 & 115 \\
$130-159$ & 54 & 55 & 60 & 169 \\
$160-189$ & 43 & 49 & 45 & 137 \\
$190-219$ & 13 & 14 & 11 & 38 \\
$220-249$ & 4 & 6 & 11 & 21 \\
$>250$ & 4 & 6 & 0 & 10 \\
Not reported & 3 & 2 & 2 & 7 \\
Total & 167 & 179 & 168 & 514 \\
Mean weight & 152.7 & 155.0 & 155.7 & 154.5 \\
\hline
\end{tabular}

TABLE IV

\begin{tabular}{ccccr}
\hline \hline $\begin{array}{c}\text { Physical } \\
\text { status }\end{array}$ & Droperidol & Secobarbital & Placebo & Total \\
\hline 1 & 65 & 69 & 67 & 201 \\
2 & 74 & 83 & 70 & 227 \\
3 & 24 & 26 & 27 & 77 \\
4 & 4 & 1 & 4 & 9 \\
Total & 167 & 179 & 168 & 514 \\
\hline
\end{tabular}

TABLE V

\begin{tabular}{lcccc}
\hline \hline History of disease & Droperidol & Secobarbital & Placebo & Total \\
\hline None & 130 & 144 & 123 & 397 \\
Cardiovascular & 16 & 16 & 16 & 48 \\
Central nervous system & 2 & 2 & 2 & 6 \\
Pulmonary & 12 & 3 & 10 & 25 \\
Miscellaneous & 11 & 14 & 25 & 50 \\
Total & 171 & 179 & 176 & $526^{*}$ \\
\hline
\end{tabular}

${ }^{*}$ Several patients reported more than one disease.

60 per cent of the patients received a sedative, usually at bedtime (Table VII). Again the distribution was similar for each group of patients.

When the patients came to the induction room after having received the study drug, they were asked to evaluate subjectively how they felt. Direct questioning was employed when indicated (Table VIII). Of particular interest were the "drowsy" and "awake" evaluations. Forty-four per cent of the patients who received droperidol indicated that they were drowsy, while the percentages for secobarbital and the placebo were 17 per cent and 8 per cent, respectively. These percentages are all significantly different from each other $(p<.05)$. Conversely, only 26 per cent of patients who received droperidol considered themselves fully awake, while after secobarbital and the placebo 45 per cent and 66 per cent, respectively, believed that they were fully awake. These percentages are also significantly different $(p<.05)$. The remaining points of evaluation were reported by almost identical percentages in the three study groups. 
TABLE VI

Patient Condition before Premedication

\begin{tabular}{lcccc}
\hline \hline Condition & Droperidol & Secobarbital & Placebo & Total* \\
\hline Alert & 156 & 162 & 152 & 470 \\
Calm & 115 & 104 & 111 & 330 \\
Nervous & 47 & 69 & 47 & 163 \\
Restless & 6 & 4 & 14 & 24 \\
Other & 7 & 13 & 12 & 32 \\
Total & 331 & 352 & 336 & 1019 \\
\hline
\end{tabular}

*Note that patients exhibited more than one condition among those evaluated.

TABLE VII

Sedatives within 24 Hours

\begin{tabular}{lcccc}
\hline \hline Sedative & Droperidol & Secobarbital & Placebo & Total \\
\hline Secobarbital & 53 & 66 & 62 & 181 \\
Chloral hydrate & 13 & 16 & 17 & 46 \\
Narcotic & 10 & 11 & 7 & 28 \\
Darvon & 23 & 23 & 15 & 61 \\
Total & 99 & 116 & 101 & 316 \\
\hline
\end{tabular}

TABLE VIII

Patient Evaluation of Premedication

\begin{tabular}{lccc}
\hline \hline Evaluation & $\begin{array}{c}\text { Droperidol } \\
\text { (per cent) }\end{array}$ & $\begin{array}{c}\text { Secobarbital } \\
\text { (per cent) }\end{array}$ & $\begin{array}{c}\text { Placebo } \\
\text { (per cent) }\end{array}$ \\
\hline Calm, relaxed & 59 & 64 & 64 \\
Drowsy & 44 & 17 & 8 \\
Neryous, upset & 34 & 31 & 31 \\
Excited & 0 & 1 & 0 \\
Restless & 3 & 2 & 1 \\
Awake & 26 & 44 & 66 \\
Afraid, scared & 4 & 5 & 2 \\
Unusual thoughts & 0 & 0 & 0 \\
Dizzy & 1 & 1 & 1 \\
Nauseated & 0 & $\mathbf{1}$ & 0 \\
Weak & 0 & $\mathbf{0}$ & 1 \\
Headache & 1 & 2 & 2 \\
Crying & 1 & $\mathbf{1}$ & 1 \\
Cold & 1 & $\mathbf{1}$ & 0 \\
Pain & 0 & & \\
\hline
\end{tabular}

The anaesthesiologist also evaluated the status of the patient objectively just prior to induction of anaesthesia (Table IX). With respect to the quality of the sedation, a "good" rating was assigned to 50 per cent of the patients who received droperidol. A similar "good" rating was applied to only 15 per cent of the secobarbital patients and 9 per cent of the placebo patients. A statistically significant $(p<.001)$ larger proportion of patients receiving droperidol were well sedated. There was no statistically significant difference in the numbers who were well sedated following secobarbital and the placebo. At the same time, only 17 per cent of the patients who received droperidol were considered to have no sedation, 
TABLE IX

Evaluation by Anaesthesiologist of Premedication

\begin{tabular}{lccc}
\hline \hline Evaluation & $\begin{array}{c}\text { Droperidol } \\
\text { (per cent) }\end{array}$ & $\begin{array}{c}\text { Secobarbital } \\
\text { (per cent) }\end{array}$ & $\begin{array}{c}\text { Placebo } \\
\text { (per cent) }\end{array}$ \\
\hline Sedation & & & \\
good & 50 & 15 & 9 \\
fair & 20 & 23 & 18 \\
slight & 11 & 24 & 18 \\
nil & 17 & 38 & 55 \\
excessive & 2 & 0 & 0 \\
Apprehension & 65 & 67 & 63 \\
absent & 22 & 24 & 26 \\
slight & 9 & 7 & 6 \\
moderate & 4 & 2 & 5 \\
marked & & 89 & 85 \\
Excitement & 87 & 10 & 13 \\
nil & 9 & 1 & 2 \\
slight & 4 & 97 & 97 \\
marked & & 3 & 3 \\
Emetic effects & 93 & 0 & 0 \\
nil & 7 & & \\
nausea & 0 & 0 & 2 \\
vomiting & & 3 & 97 \\
Local irritation & 0 & 97 & \\
marked & 1 & & \\
slight & 99 & & \\
nil & & & \\
\hline
\end{tabular}

whereas the percentages for secobarbital and the placebo were 37 and 55, respectively. In the remaining parameters, there were no significant differences in the proportions between the groups.

Consideration was also given to the changes in respiration, pulse rate, and blood pressure, as recorded on the ward the afternoon before surgery, and as present after premedication but just prior to induction of anaesthesia (Table X). Respiratory dynamics appeared to be unchanged by any of the premedicant drugs. As might be expected, there was a tendency for the pulse rate and blood pressure to be increased just prior to surgery in all patients. However, the mean values of the pulse rate changes between the drugs were not statistically significant. But the mean increases in systolic and diastolic blood pressures at the time of induction were significantly less $(p<.01)$ in the droperidol group than they were in patients who received secobarbital or the placebo. Induction of anaesthesia was not influenced adversely in any patient.

\section{Discussion}

It is recognized that a study such as this, which relies to some extent on subjective evaluations in an unselected patient population, is open to limited interpretation. However, the relatively large sample size and the homogeneity of the patient groups lend credence to the positive results.

The doses of droperidol and secobarbital that were chosen for the study were on the small side. Unfortunately, in a double-blind study it is not possible to individualize the dose, and it is likely that under normal circumstances one would 
TABLE $X$

Effect of Study Drugs on Vital Signs

\begin{tabular}{|c|c|c|c|c|c|c|}
\hline \multirow[b]{2}{*}{ Vital sign } & \multicolumn{2}{|c|}{ Droperidol } & \multicolumn{2}{|c|}{ Secobarbital } & \multicolumn{2}{|c|}{ Placebo } \\
\hline & premed. & induction & premed. & induction & premed. & induction \\
\hline Pulse rate & 79.4 & 80.8 & 78.7 & 80.7 & 78.4 & 83.3 \\
\hline BP (systolic) & 122.7 & 128.0 & 121.9 & 135.0 & 122.3 & 135.5 \\
\hline BP (diastolic) & 78.3 & 79.6 & 79,3 & 85.5 & 78.9 & 83.8 \\
\hline
\end{tabular}

have prescribed larger doses to some patients. However, previous experience indicated that the doses chosen were safe, and it was believed that, if effectiveness could be shown at this dosage, anaesthesiologists in the future could be guided accordingly. These concepts were borne out by the results, which indicated that only two patients, both of whom received droperidol, were believed by the anaesthesiologist to be excessively sedated.

In this double-blind study, it was notable that droperidol caused significantly more patients to feel drowsy than did secobarbital or the placebo. Conversely, a larger number of patients who received secobarbital or the placebo considered themselves awake. The action of secobarbital in producing a subjective state of drowsiness in the dosage employed was not as effective as droperidol.

Of even more significance was the rating applied by the anaesthesiologist to the adequacy of the sedation provided by droperidol. Secobarbital ran a poor second in this respect, and the effect of the placebo was as might be expected. The absence of respiratory and cardiovascular depression, as measured at the time of induction, with the production of good sedation, is a desirable combination for premedication. The lesser increase in blood pressure seen at the time of induction in the patients who received droperidol could be a result of the sedation achieved, or it could be secondary to the mild adrenergic blocking action associated with doses of the order administered.

\section{SUMMARY}

1. In a double-blind study involving 514 adult patients, a comparison was made of the effectiveness and safety of droperidol and secobarbital as premedicant drugs prior to anaesthesia and surgery.

2. The three groups studied (the third group receiving a placebo) had a homogeneity of distribution which gives credence to the results.

3. Subjectively, droperidol produced drowsiness in a significantly larger number of patients, statistically, than did secobarbital or the placebo.

4. Objectively, droperidol was rated as providing good sedation in a significantly larger percentage of patients, statistically, than received secobarbital or the placebo.

5. Untoward effects on the respiratory or cardiovascular systems were not seen following either of the premedicant drugs employed.

6. Droperidol is believed to be a useful, safe, and effective drug for premedication. 


\section{RÉSUMÉ}

1. Dans une étude à double inconnu comprenant 514 malades adultes, on a comparé l'efficacité et la sécurité du dropéridol et du sécobarbital comme agents de prémédication.

2. Les trois groupes étudiés (le troisième groupe recevait du placebo) étaient distribués de façon équitable ce qui donne de la valeur aux résultats.

3. Subjectivement, le dropéridol a produit de la somnolence chez un nombre de malades sensiblement supérieur à ce qu'on a observé pour le sécobarbital ou le placebo.

4. Objectivement, le dropéridol a produit une bonne sédation dans un pourcentage sensiblement supérieur à ce qu’ont donné le sécobarbital ou le placebo.

5. Dans aucun des trois groupes on n'a observé d'effets désagréables.

6. On croit que le dropéridol est un produit utile, sûr et efficace en prémédication.

\section{ACKNOWLEDGMENTS}

We are much indebted to Miss Lena Dahlstrom for technical assistance and to Mr. T. W. Teal for statistical analysis. This study was supported by McNeil Laboratories, Fort Washington, Pennsylvania.

\section{REFERENCES}

1. Janssen, P.; Niemegeers, C.; Schellekens, K.; Verbrugcen, P.; \& Van Neuten, J. The Pharmacology of Dehydrobenzperidol, a New Potent and Short-acting Neuroleptic Agent Chemically Related to Haloperidol. Arzniemittel-Forsch. 13: 316 (1963).

2. YelnovskY, J.; Katz, R.; \& Dietrich, E. A Study of Some of the Pharmacological Effects of Dehydrobenzperidol. Conference on the Use of Phentanyl and Dehydrobenzperidol, University of Pennsylvania Hospital, Sept. 25, 1962.

3. De Castro, G. \& Mundeleer, P. Dehydrobenzperidol et Phentanyl: deux anesthésiques nouveaux qui apportent de nouvelles possibilities à la neuroleptanalgesie. Proc. Symp. Neuroleptanalgesia, First European Congress of Anesthesiology, Vienna, 1962.

4. Ferrari, H. A. \& Stephen, C. R. Neuroleptanalgesia: Pharmacology and Clinical Experiences with Droperidol and Fentanyl. South.M.J. 59: 815 (1966).

5. Ferrari, H. A.; Thompson, L. W.; Talton, I.; \& Stephen, C. R. Variations in Arterial Blood Values before, during and after Neuroleptanalgesia. South.M.J. 61: 947 (1968). 